\title{
Discussion on the Asset Allocation of Chinese Investors in the Post-Epidemic Period
}

\author{
Zhihang Lu*, Xiangjing Jia
}

Nanjing University of Information Science \&Technology, Nanjing 210044, Jiangsu province, China. Email: 201733060067@nuist.edu.cn

\begin{abstract}
In 2020, a sudden COVID-19 epidemic sweeping across the world, it will have an indelible and significant impact on China and even the world economy. Asset price fluctuations increase in the real estate, bonds, stocks, bulk commodities and other investment markets, and the risk is in aggravation. Therefore, since our country is to build the domestic large cycle as the main body, and the bi-circulating promotes mutually, the new development pattern of domestic and international macroeconomic growth is expected to accelerate. This paper, from the monetary policy, the view of the present situation and the types of investors in financial markets, analyses the main points of the investors' capital allocation outbreak era and the reasons, and provides a reference for readers.
\end{abstract}

Keywords: Epidemic Situation; Investor; Asset Allocation

\section{Monetary policy}

At the beginning of 2020, the People's Bank of China set up the first batch of special re-loans of 300 billion yuan on January 31 at the initial stage of the epidemic outbreak, supporting banks to provide loans with preferential interest rates to key enterprises of medical care and living materials. The government gave $50 \%$ discount interest rates, which greatly supported the development of enterprises. At the same time, China's M2 money supply exceeded 200 trillion yuan for the first time. Since the reform and opening-up, China's M2 money supply has been growing at an average annual rate of 15 percent. However, the rate of return on most financial assets is not better than the printing machine, but the essence of issuing money is always to promote the steady operation and development of the economy ${ }^{[1]}$. Through deepening the reform of loan market quoted interest rate (LPR), the financial management department promotes the reduction of loan interest rate, implements two direct monetary policy tools and reduces fees, to promote the financial sector and make profits to the real economy. It is estimated that the target of 1.5 trillion yuan has been achieved by the end of December 2020. In the next period, the People's Bank of China will adhere to seek improvement in stability and implementation of prudent monetary policy, keep the money supply basic matching with nominal GDP growth, do well across the cycle of policy design, promote reform of the supply side, sustained-release potential LPR reform and strengthen loan real interest rates decline cost to restore production and operation in every walks of life and improve the macro economy.

In addition, the government's monetary policy has a very important impact on the trend of China's real estate market. At present, the central bank pointed out that "housing is not speculation". Coupled with the epidemic situation, the real estate industry is depressed. And the future development space of the real estate enterprises does not lie in the ap-

Copyright (C) 2021 Zhihang Lu et al.

doi: $10.18686 /$ fm.v6i1.3170

This is an open-access article distributed under the terms of the Creative Commons Attribution Non-Commercial License

(http://creativecommons.org/licenses/by-nc/4.0/), which permits unrestricted non-commercial use, distribution, and reproduction in any medium,

provided the original work is properly cited. 
preciation of the room, but the competition for the stock market share. The Chinese government has stopped stimulating real estate as a means of driving the economy, so investors should be cautious about investing in the sector.

\section{Financial markets}

\subsection{Stock market}

By January 17, 2021, China's SSE index was close to the 4000 marks. Since China took the lead in controlling the epidemic. China's stock market has been greatly sought after by domestic and foreign funds, and the domestic economy is optimistic in the long run ${ }^{[2]}$. Among them, the indexes of consumption industries such as liquor and new energy vehicles are far ahead, and the ChiNext market is dominated by technology stocks, has risen by $77.13 \%$. The new economy, such as online medical treatment, short video, online education and online office, is magnificent, which not only opens the gap with traditional value stocks but also hits new highs. Although the index is on the rise reaching one -trillion trading volume, the effect of making money is still not very strong. Investors' positions should be kept in the vicinity of the 4 storehouses, beware of the periphery of the epidemic and capital departure.

From the perspective of business performance, the operating conditions of listed companies have a strong positive correlation with GDP. Usually, high GDP growth also drives the A-share market earnings. Structural characteristics lead to the industry turns up, such as last year's outstanding profitability of medical care, Internet technology, liquor is likely to be back. And in the future for a while, this article is optimistic about the service, consumer business conditions of the improvement. In terms of investor sentiment, the market is very dynamic with both old and new retail investors running into the market in recent months ${ }^{[3]}$. From the position of the public offering fund, the current public offering fund stock positions only have 6 positions, and the distance from the top of the 8 positions still have a certain space. Therefore, in the case of market rotation, stable investors should choose good quality, stable performance of blue-chip stocks, and investors with higher risk preference can choose the unicorn of over-fall rebound, do a good job of perfect investment strategy.

\subsection{The bond market}

China's fixed income bonds, especially national debt with high credit rating are price sticky in adjustment, and the yield performance of fixed income bonds is poor in the years of rapid monetary growth. According to Zepin Macro and Wind database, the average yields of 3-month, 1-year, 3-year, and 10-year bonds from 2002 to 2017 were 2.4\%, 2.6\%, $2.9 \%$ and $3.56 \%$, respectively, which were not only far lower than the growth rate of broad money but also lower than the price growth rate of other commodities and the yield rate of assets. According to historical data, the yield of stocks and bonds has an inverse relationship. At present, the yield of 10-year government bonds is in an upward trend, which is close to the average value of nearly 10 years. Although the investment value of stocks is higher than bonds at present, we expect that the economic growth rate will gradually decline in the second half of 2021, which may gradually form a good time for bond investors.

\subsection{Commodity market}

In the first half of 2020, the epidemic caused economic stagnation, resulting in a sharp decline in commodity prices and insufficient stock. However, in the fourth quarter, the economy recovered, and commodity prices rose. On the whole, most bulk commodity index is given priority to with fall. Specifically, as supply and demand is different, each fine item yield rate also differs somewhat. Precious metals, for example, ended the day up across the board with silver up 47.38 percent and gold up 24.42 percent, as investors favored the safe-haven nature of such physical assets. In terms of agricultural products, the overall trend in 2020 will first fall and then rise. Class of commodities almost uniformly fell more than 20 percent. After negative interest rates, it has negative oil prices. Since 2020, the dollar has continued to weaken, while gold and bitcoin have continued to strengthen. However, the trend of gold and bitcoin is different, when the risk preference of the market changes due to the launch of the vaccine. When the risk preference decreases and the dollar weakens, it is better to invest in gold. When the risk preference increases and the dollar weakens, it may be a bet- 
ter choice to invest in bitcoin. This paper believes that the depreciation of the US dollar and the enhancement of liquidity are conducive to the further return of commodity prices, and their investment returns may exceed the stock market. Demand is gradually recovering, and the pattern of the supply side is further expanding.

\section{Suggestions for asset allocation in the post-epidemic period}

The future cannot be predicted, just as the new epidemic has been unexpected. However, as an investor, in the case of decentralized allocation of global assets, based on the quantifiable signal indicators of the system, we should go along with the trend, make a phased tactical strategy and select the major category of assets with the maximum benefit according to our situation. Therefore, looking forward to 2021, this paper proposes the following five suggestions.

\subsection{Be careful to invest in real estate}

Real estate investment is not recommended. As China's real estate industry has been nearly saturated, the government has strengthened control and clarified the role of real estate's physical value. Although real estate is one of the three driving forces of China's economic growth, the consequence of overweighting the real estate investment will be a huge systemic risk and a huge disaster for most individual investors once it happens. Therefore, residents should adjust the existing investment concept and rental house in priority.

\subsection{Focus on the stock market in the short term}

In the short term, the focus can be on the domestic stock market ${ }^{[4]}$. At present, the proportion of speculative capital of Chinese investors is too large, and there is a general lack of long-term investment thinking. With the gradual improvement of China's capital market, the gradual improvement of investors' financial literacy, coupled with foreign funds optimistic about domestic economic development, the A-share market gradually develops to a good trend beyond doubt. It should be noted, however, that investors with different risk preferences should choose different portfolios. According to CAPM (Capital Asset Pricing Model), the greater the $\beta$ coefficient is, the higher the risk is; the smaller the $\beta$ coefficient is, the lower the risk is. Conservative investors should choose small beta coefficient. Therefore, securities investment can pick and choose the good operating performance, and blocked during the outbreak of state-owned enterprise stocks and ETFs. Stock funds to a basket of the securities portfolio can obtain high returns and effectively reduce the risk of short-term, and investors can appropriate focus on consumption and the energy sector. For those investors with a higher risk preference, this paper suggests holding no more than 6 layers. According to Bloomberg data, the yield of the stock market has reached the average level in recent years. In order to prevent the stock market from falling back, it is still necessary to keep a rational mind to make investment decision analysis.

\subsection{The Chinese cultural market is promising for a long time}

The investment value of artworks tends to increase. The state has issued relevant policies to encourage the development of cultural industries and support cultural and creative fields such as artworks. As a cultural and creative industry, artwork plays a pivotal role in the optimization of the industrial structure due to its low consumption, high added value and value-added potential. While enriching people's spiritual life, artworks have more and more financial attributes. Unlike in the housing market, where overinvestment led to a bubble, or in the subprime crisis, there is no limit to the value of art. Because real estate is a cycle of 18 years, the real estate investment will experience periodic boom and bust ${ }^{[5]}$. As a cultural product, the artwork is not restricted by the economic cycle. But with the continuous improvement of the acceptance and recognition of artwork in the cultural market, its value will tend to increase. The artworks in the secondary auction market through professional evaluation and identification, which will also improve its liquidity in the transaction to reach the effective value transformation and embodiment. Therefore, in the current macro environment of loose monetary policy, investors need to choose the assets that are least affected by the economic cycle to allocate. The practice has proved that the correlation coefficient among art investment, A-share investment and real estate investment is very low, and the value does not fluctuate with the economic cycle, so it is an ideal asset allocation that 
can withstand the test. At present, Chinese style and Chinese cultural and creative products are being integrated into residents' lives. The rising tide of local countries is bound to drive the vigorous development of a series of local industries, thus promoting overall economic growth.

\subsection{IPO new and fund investment in parallel.}

According to Bloomberg data, last year, both the number of IPOs and the proceeds set a record in a decade. The performance of new stocks has been even more impressive. In 2020, 430 billion new shares were issued, and science and innovation version financing took the lead less than 30 stocks broke. Last year, the yield of liquor in China was as high as $150 \%$. But whether it was the dot-com bubble in 2000 or the subprime mortgage crisis in 2008, there is no risk-free return. Therefore, for these two plates, this paper suggests appropriate configuration according to their situation, which should not be too high.

\subsection{Properly configured commodities}

Commodities are expected to have a new bull market. The bottom of the domestic commodity market is well supported. At present, under the conditions of domestic monetary policy easing, more money will naturally flow into the commodity, bringing the overall rise of commodity prices. A global recovery will push commodity prices higher on the demand side, but it should beware of a dip in the second half of $2021^{[6]}$. When the economy grows too fast in the first half of 2021 and the inflation rises too much, it will inevitably bring about the rapid contraction of the monetary policy of the global central bank, which will lead to the decline of commodity prices in the second half of the year. Therefore, to make investment variety, investors should have excellent investment means the investment vision and preparation. Timely stop loss, see good close.

\section{Conclusion}

As an investor, on the one hand, we should pay attention to the dynamic changes of the market and current political hot spots; on the other hand, we should improve our financial literacy and enhance our ability to resist risks, so as to maximize benefits in the uncertain future trend of the world economy. Therefore, it is necessary to do a good job in capital management, choose the right time to enter the market, formulate profit targets and loss limits, take investment as a career to do, constantly improve themselves, constantly improve their skills and combine skills, knowledge, mentality and market game.

\section{References}

1. Tang Y. Analysis of the current situation and countermeasures of Chinese household financial asset tion based on the data of Chinese household financial survey (CHFS). Economic Forum 2018; (08): 41 - 44.

2. Guo D, Wang R. Research on the relationship between monetary policy and real estate price under the economic cycle. Journal of Mudanjiang Normal University 2020; (01): 1 - 12.

3. Yuan J, Yuan X, Zhang C, et al. Asset allocation against “epidemic” approach. China Foreign Exchange 2020; (06): $62-64$.

4. Section Phase Domain. The present situation and optimization strategies of household financial assets allocation in china. National Circulation Economy 2020; (16): 146 - 147.

5. Shang Y, Xu W. Research on industry asset allocation in stock market based on business cycle. Economic Problems 2020; (03): 25 - 34.

6. Yuan H. Effects of novel coronavirus epidemic on Chinese economy and countermeasures. China Small and Medium Enterprises 2020; (03): 56 - 57. 